\title{
Evento Anual de las Sociedades Científicas de la Unión Nacional de Juristas de Cuba
}

La vía de lesividad administrativa: utopía vs. realidad en el ordenamiento jurídico cubano

Dra.C. Grethel Arias Gayoso ${ }^{1}$ | Universidad de Oriente

Revista Derechos en Acción ISSN 2525-1678/ e-ISSN 2525-1686

Año 4/No 12 Invierno 2019 (21 junio a 20 septiembre), 725-758

DOl: https://doi.org/10.24215/25251678e.324

\section{A modo de introducción: iniciando la reflexión}

Cuando se piensa en el actuar de la Administración Pública la referencia más inmediata que acude es la relacionada el poder de una persona cuyas decisiones emergen con la presunción de validez que determina, en el destinatario del acto, la obligatoriedad de su cumplimiento, previo, incluso, a cualquier reclamación. De tal manera se alza la Administración Pública como un sujeto tan intenso que no precisa demostrar que suxs declaraciones de voluntad, deseo, conocimiento o juicio (usando los términos con que describiera $\mathrm{ZANNOBINI}^{2}$ al acto administrativo) son menos que obligatorias. Por supuesto, la percepción del ejercicio de potestad que subyace en su nacimiento, contribuye a esta concepción; así como otros muchos elementos heredados de aquella Administración decimonónica y omnímoda. Pese a ello, el Derecho Público contemporáneo, y sus constantes

\footnotetext{
1 Licenciada en Derecho por la Universidad de Oriente, Santiago de Cuba. Doctora en Ciencias Jurídicas. Profesora titular de Derecho Administrativo, (UO).

2 Guido ZANOBINI, Curso de Derecho administrativo, Volumen I, Parte General. Trad. de la 5ta. Edición italiana por Héctor MASNATTA y actualizada con la 6ta edición por Francisco Humberto PICONE, Ediciones ARAYU, Buenos Aires, 1954, p. 412.
} 
mutaciones, inclina el eje hacia el fortalecimiento del interés público representado y gestionado por la Administración, y hacia la figura de un administrado cada vez menos pasivo en sus relaciones con el sujeto administrativo.

Si bien, el interés privado debe inclinar su "bandera" ante la preponderancia de valoración de un interés público; también para la Administración resulta impensable defender otro interés que no sea el público. De esta coyuntura, y bajo ella, emerge la noción de la lesividad administrativa, una institución que cuestiona los cimientos de ejecutividad del acto administrativo ante la afectación a un interés público. Una institución que permite humanizar a la Administración Pública, demostrando que sus facultades para evaluar lo verdaderamente conveniente al interés público han de ser superiores a la aplicación mecánica y ortodoxa de su voluntad.

Sin embargo, la realidad jurídico administrativa cubana no ofrece rasgos que nos indiquen - más que el su reconocimiento normativo -, que es la lesividad una vía para confiarle a la Administración la protección del interés público por encima de sus declaraciones anteriores de voluntad. Parecería como si la Administración, entronizada en sus decisiones, fuese incapaz de reconocer que sus actos, bajo determinadas circunstancias no previstas al momento de emitirlos, puedan tornarse lesivos, y sea preciso recabar sobre los mismos en nombre de la garantía absoluta de proteger el interés público.

Bajo estas ideas iniciales se enfocan estas líneas, representadas por el ideal de convertir a la Administración Pública cubana en una Administración cada vez más eficiente y funcional.

\section{La lesividad administrativa: de su construcción teórica. Una mirada necesaria al acto administrativo}

Como ya se ha introducido, la idea de la lesividad y su instrumentación procesal, constituyen una garantía en su máxima extensión. No sólo para los derechos de los administrados, pues se limita así la posibilidad de que la Administración revoque sus 
actos por sí misma y con ello afecte los intereses privados de los administrados; sino también para el interés público y con él, la preservación de un orden en el que incide más lo general, lo de todos, que el interés personal. A su llamado acuden dos principios generales para sostener su necesidad: los principios de legalidad y de seguridad jurídica.

Es indudable que el proceso de lesividad imposibilita que se violente el espacio jurídico de los administrados y constituye a su vez un remedio procesal ante los actos de la Administración que atenten contra el interés público que debe primar en cada decisión administrativa; lo que incide de forma positiva en el perfeccionamiento de la actividad de la Administración Pública.

Sin lugar a dudas, la institución primaria que destaca en cualquier acercamiento a la lesividad, es el acto administrativo. Sin una declaración de voluntad previa es imposible pensar en una afectación posterior.

En tal sentido afirmamos que el acto administrativo desde su nacimiento se presume válido, y, una vez notificado se presume legítimo, pues emana de las potestades de orden público que tiene la Administración y que persigue el interés general; además posee fuerza vinculante para la persona a quien va dirigido. El acto administrativo goza también de estabilidad, ya que forma parte del ordenamiento jurídico y de las instituciones administrativas porque confieren derechos, establecen obligaciones y regulan la relación existente entre la Administración Pública y los administrados. De ahí que el autor José GASCÓN Y MARÍN, refiera que el acto administrativo tiene varios caracteres como son la legitimidad, oportunidad, ejecutoriedad y revocabilidad $^{3}$, a lo cual añadiríamos la ejecutividad que deriva, presumida, de la propia legitimidad del acto administrativo.

En la concurrencia de vicios atinentes a los elementos del acto y su posible y futura determinación de revocación,

3 GASCÓN Y MARÍN citado por Pedro CARRILLO, " La ejecutoriedad del acto administrativo" en Revista Jurídica Argentina La Ley, editorial La Ley, Buenos Aires, Argentina, 1945, p. 871. 
concurren, en términos de Manuel María DIEZ, tanto por motivos de legitimidad como por causas de mérito, aludiendo que en el caso de la primera, la revocación afecta a los actos que nacieron válidos y que luego por las causas supervinientes ${ }^{4}$, conviene retirarlos del mundo jurídico; y en el supuesto de la revocación por razones de mérito, se refiere al retiro del acto por la existencia de nuevas circunstancias de hecho o por apreciación del interés general.

Además de ser entendida la revocación como un modo de extinción del acto administrativo, ha sido estudiada como parte de la revisión de oficio que puede realizar tanto la propia Administración Pública como el órgano jurisdiccional competente, entendida ésta como el genus, el género común del que podemos diferenciar posteriormente dos especies o variedades, a saber, la revocación de actos administrativos y la anulación de actos administrativos, en este último caso a su vez por causa de nulidad o de anulabilidad. ${ }^{5}$

Entre la revocación y la anulación existen diferencias marcadas por las realidades diversas que poseen. Esa diversidad o diferenciación se alcanza con plenas garantías atendiendo verdaderamente al fundamento de la revocación, como expresara GARRIDO FALLA, esto es, basar todo el edificio revocatorio o anulatorio, según proceda, en un criterio objetivo donde los conceptos clave que adquieren todo el protagonismo son los de oportunidad e ilegalidad del acto. De este modo y atendiendo exclusivamente a su sentido originario más estricto, cuando la extinción o eliminación del acto se reconduce a simples motivos de oportunidad, incompatibilidad con el interés público, conveniencia administrativa o incluso por causas de mérito, ese supuesto constituye una indubitada revocación; mientras que si la eliminación del acto trae causa de su presunta ilegalidad, no

\footnotetext{
4 Estas causas pueden ser consecuencia de una modificación de las normas legales que torne inválido el acto que había nacido válido.

5 Antonio FORTES MARTÍN, "Estudio sobre la Revocación de los actos administrativos", en Revista de Derecho Vol. XIX-No. 1-Julio 2006, pp. 151-152.
} 
queda otro remedio que calificar ese caso como de anulación, o invalidación.

Por otra parte, produciéndose la revocación del acto favorable por una u otra vía, la acción revocatoria debe llevar aparejado el reconocimiento de la indemnización procedente en la persona que sufre los rigores de la revocación. La indemnización opera así como un instrumento garantista y resarcitorio por la lesión patrimonial sufrida, incluso en aquellas posturas doctrinales que estiman que verdaderamente, y en lugar de un supuesto de revocación, se produce una auténtica expropiación de derechos.

La revocabilidad de los actos administrativos es una de sus características que constituye un privilegio para la Administración, sin embargo no todos los actos administrativos pueden ser revocados y en especial no son revocables por razones de legitimidad o conveniencia los actos que han engendrado derechos subjetivos $^{6}$. ZANOBINI ${ }^{7}$ sostiene que es necesario que el derecho subjetivo sea perfecto para que el acto no pueda revocarse. Son revocables los actos que atribuyen un derecho condicionado de los que surgen, intereses protegidos ocasionalmente, ya que estos derechos e intereses no podrían estar en conflicto con el interés público.

La irrevocabilidad de los actos administrativos que crean derechos subjetivos está dada según la doctrina ${ }^{8}$ por dos cuestiones

6 El derecho subjetivo es la posibilidad de exigir de otro el que obre o se abstenga de hacerlo, este existe tanto en el Derecho Público como en el Derecho Privado, el Derecho Subjetivo público es una consecuencia de las relaciones jurídicas que suelen crearse entre el Estado y los particulares. Los derechos subjetivos pueden ser afectados por la ley cuando esta posee efectos retroactivos porque así lo demandan razones de carácter social y son incompatibles con la realidad que nos ofrece cualquier Estado moderno.

7 Citado por Manuel María DIEZ, El acto..., ob. cit., p. 331.

8 Antonio FORTES MARTín, "Estudio sobre la Revocación..." ob. cit., pp. 151 y ss.; GONZÁLEZ PÉREZ, "La revocación de los actos administrativos en la jurisprudencia española”, en Revista de Administración Pública, No.1, Enero-Abril, Instituto de Estudios Políticos, Madrid, pp. 109 y ss.; Laureano LÓPEZ RODO, “Presupuestos subjetivos para la aplicación del principio que prohíbe ir contra sus propios actos" en Revista de Administración Pública, No. 9, Septiembre- Diciembre 1952, Instituto de Estudios Políticos, Madrid, pp. 26 y ss.; Allan 
esenciales, la primera de ellas es el principio del non venire contra factum proprium (nadie puede ir en contra de sus propios actos) y la segunda es la trascendencia que posee un acto administrativo que reconozca derechos subjetivos.

La Administración Pública, como sujeto colectivo, está integrado por multitud de órganos con personalidad jurídica, colocados en distintos planos jerárquicos y de los cuales emanen actos imputables al sujeto colectivo que serán considerados actos propios. No obstante, lo anteriormente expuesto, no implica que cada órgano no cuente con independencia en su actividad administrativa y por ello cada acto que realice en su marco competencial será denominado acto propio de ese órgano en específico y no de otro que igualmente pertenezca a la Administración Pública. De ahí que la regla general siga siendo la que prohíbe la impugnación de los actos de otro órgano del mismo sujeto colectivo.

Como ya hemos planteado, cada órgano posee una jerarquía interna en virtud de la cual los actos realizados por el superior jerárquico tienen la consideración de actos propios para el inferior, lo que implica que deben siempre ser respetados por el subordinado. Basado en tal motivo, el autor JORDANA DE POZAS $^{9}$ incluye entre los casos de irrevocabilidad de los actos administrativos el de haber sido confirmados por el superior, la confirmación de la autoridad superior impide al inferior volverse contra el acto primitivo.

Es por ello que la clave de la potestad revocatoria de la Administración se encuentra en la tensión que se origina entre,

\footnotetext{
Randolph, BREWER CARÍAS, “Comentarios sobre la Revocación de los actos administrativos", en Revista de Derecho Público, No. 4, Caracas, 1980, p. 28-30.; LÓPEZ DE HARO, "Los actos propios y en la Jurisprudencia del Tribunal Supremo", en Revista de Derecho Privado, 1913, pp. 18 y 19; Puic BRUTAU, Actos propios, en Nueva Enciclopedia Jurídica, Seix, editor. Barcelona, 1950, pp. 348- 351.; Adolfo MERKL, Teoría General del Derecho Administrativo, Editorial Revista de Derecho Privado, Madrid, 1935, p. 14.; Eduardo GARCÍA DE ENTERRÍA, "La doctrina de los actos propios y el sistema de lesividad" en Revista de Administración Pública, No. 20, Mayo-Agosto, Instituto de Estudios Políticos, Madrid, 1956, pp. 69 y ss.

9 Luis JORDANA DE POZAS, Derecho Administrativo, Madrid, 1924, p. 59.
} 
por un lado, el interés público a la modificación o revocación de la situación existente y, de otro lado, la seguridad jurídica del particular al mantenimiento de su status quo intangible, aspecto este que, tradicionalmente, se ha venido sustentando en el ya mencionado principio de irrevocabilidad de los actos y que parece encontrar también un importante asidero en la llamada confianza legítima generada por la Administración Pública.

Las limitaciones de la revocación provienen de ciertos principios jurídicos ${ }^{10}$ que tienen por finalidad proteger los derechos y situaciones jurídicas favorables del destinatario del acto administrativo. Pero no por ello la Administración queda atada a la irrevocabilidad, sino que cuando el interés público reclama una rectificación, puede acudir al órgano judicial para que anule el acto lesivo. Por lo que puede anticiparse que el fin último de la revocación de todo acto administrativo vendrá determinado por una motivación externa traducida en un interés público; interés público que sirve de fundamento a la revocación y que puede responder o no a las mismas razones de interés público que tuvo en cuenta inicialmente la Administración para dictar el acto cuya revocación ahora pretende.

La consecución del interés público representa para la Administración Pública el fin de toda su actividad, y la dinamicidad que le imprime a su quehacer esta interacción es clave para su funcionalidad. La noción de interés general es fundamento y límite de las potestades administrativas; éstas no existen más que en la medida que determina el interés general. El interés general constituye, pues, la medida de los poderes de la Administración.

\footnotetext{
10 Nos referimos a los principios de legalidad, irrevocabilidad de los actos administrativos declaratorios derechos y seguridad jurídica; el primero de estos encaminado a mantener el orden legal de los actos cuando han nacido con todos los requerimientos necesario para surtir los efectos para los que fue dictado; mientras que la irrevocabilidad de los actos administrativos impide a la Administración Pública revocar un acto que goza de validez y por ende es legítimo y legal; y por último el principio de seguridad jurídica le impide a la Administración Pública actuar a su libre albedrío, sino que, debe solicitar la revocación de sus actos mediante el mecanismo legalmente establecido y ante la autoridad competente para ello.
} 
La Administración Pública, como ya hemos expresado, no puede revocar por sí misma los actos mediante los cuales se hayan creado derechos subjetivos a particulares; por lo cual está obligada a acudir a la vía contenciosa administrativa para solicitar a éste órgano la revocación de su propio acto, bajo el criterio de que es lesivo al interés público representa. Ahora bien, esta potestad discrecional que ostenta la Administración Pública para declarar perjudicial al interés público un acto o contrato administrativo es un requisito para el ejercicio de la acción revocatoria ante los tribunales competentes.

La potestad de declarar lesivo un acto administrativo es de carácter discrecional y está conferido a la Administración para proteger los intereses públicos, esta potestad solo admite aquellas restricciones expresamente establecidas por la Ley para garantía y seguridad del interés particular.

En el conflicto de un interés particular frente al interés público, debe hallarse una fórmula, que sin detrimento sustancial del interés privado y sin desprecio de lo justo, permita dar preferencia y satisfacción al interés general; de ahí que, la Administración pueda discrecionalmente declarar lesivo al interés público un acto administrativo sin ejercitar esta potestad de modo arbitrario o abusivo al interés del particular, que goza de protección jurídica, sino que su ejerció debe inspirarse siempre en las razones de conveniencia pública en que se fundamenta esta potestad.

Para que un acto administrativo sea declarado lesivo se requiere que haya causado estado. El hecho de causar estado ha sido en muchas ocasiones confundido con la firmeza del acto, así como con las denominadas resoluciones definitivas. Causan estado, según Manuel BUSTELO VÁZQUEZ, "las resoluciones de la administración cuando no sean susceptibles de recurso en la vía gubernativa, ya sean definitivas, ya de trámite, si estas últimas deciden directa o indirectamente el fondo del asunto, de tal modo que pongan término a aquella o hagan imposible su continuación". ${ }^{11}$

11 Manuel BUSTELO VÁZOUEZ, ob.cit., p. 44 
El mismo autor refiere que la revocación es un acto de voluntad y solo puede verificarse por la misma voluntad que le dio origen, por lo que: "nadie puede apreciar mejor que ella si un acto o negocio resulta lesivo a sus intereses". ${ }^{12}$

La declaración de lesividad es un trámite inexcusable para el ejercicio del recurso de lesividad; su finalidad es, precisamente, la de autorizar la admisión y trámite del correspondiente recurso. En realidad, el fundamento de la referida declaración está en que, siendo el proceso de lesividad excepcional, se quiere asegurar que la Administración, antes de iniciarle, está convencida de la lesión, obligándola a dictar formalmente tal declaración.

En relación a la existencia del proceso contencioso de lesividad se han construido varias tendencias, por contradecir en sí mismo el principio general de que nadie puede ir válidamente contra sus propios actos, aspecto que resulta de vital importancia para la comprensión de esta institución. ${ }^{13}$

Uno de estos criterios se inclina por la no procedencia del recurso de lesividad, basado en que, a partir de la defensa de la Administración Pública sin sus injustificados privilegios, la misma no puede volver sobre sus propios actos, porque siendo en todo caso emanación de autoridad y debiendo acatarlos los administrados, que pueden hacer de ellos base de su actividad, sería una injusticia que se admitiese la posibilidad de deshacer lo hecho, quedando así en el aire la seguridad de los que al amparo de una resolución procedieron. Y si se cree necesario el volver sobre los actos declaratorios de derechos y, por tanto, irrevocables por la Administración, como ello representa una derogación legal, no debe tener la Administración otro medio que acudir a la fuente suprema de la autoridad.

FERNÁNDEZ MOURILLO ${ }^{14}$ defiende la existencia del proceso de lesividad y lo fundamenta como una excepción a la

\footnotetext{
12 Idem., p. 50.

13 Jesús GONZÁLEZ PÉREZ, Derecho Procesal Administrativo, $1^{\text {a }}$ ed. Tomo 3, Instituto de Estudios Políticos, Madrid, 1958, p. 129.
}

14 Exponente de esta postura es FERNÁNDEZ MOURILLO, Lo contencioso...., ob.cit., p. 55. 
facultad que posee la Administración de actuar por sí y como una excepción al principio de la irrevocabilidad de los actos administrativos declaratorios de derechos, al establecerse la posibilidad de la Administración de revocar sus propios actos. Además, argumenta que la imposibilidad de modificar por la propia Administración sus actos declaratorios de derechos sirve para equilibrar los intereses públicos con los particulares, brindándole mediante el proceso de lesividad mayores garantías al particular ante la posibilidad de que puedan privarse de sus efectos los actos emanados de la Administración; cuestión que sin dudas tendrá una mayor garantía con la intervención del órgano judicial competente. Esta intervención del órgano judicial como garantía para los administrados es el sustento del principio de seguridad jurídica.

El principio de respeto a los derechos adquiridos se erige así en barrera, la Administración no podrá revisar sus actos, cuando creen, declaren o reconozcan derechos a favor de terceros; sin embargo, en polo contrapuesto el interés público y su gestión por la Administración, obligando en pos de las exigencias de aquel interés general y la necesaria legitimidad del actuar administrativo, a que la Administración puede declarar sus propios actos lesivos al interés público, y solicitar su revisión.

\section{II.a) Dos principios básicos para la comprensión de la lesividad: el non venire contra factum proprium y el principio de irrevocabilidad de los actos favorables en su derivación al principio de buena fe}

Como ya se ha explicado, la existencia de la lesividad administrativa, responde, esencialmente a la necesidad de retirar del tráfico jurídico un acto que ha devenido en lesivo al interés público. Sin embargo, esta realidad se sustenta en la existencia de principios jurídicos que prevén la pertinaz toma de decisiones cuando se trata de situaciones en las que un acto administrativo constituye el epicentro de la discusión. No obstante, la situación que se genera es mucho más amplia. El principio del 
non venire contra factum proprium no opera, exclusivamente, para las decisiones individuales, sino también para aquellas generadas mediante reglamentos; de lo que se trata, en realidad, es de aplicarlo en defensa de los derechos, sin recabar en la naturaleza de la decisión que genera la afectación ${ }^{15}$. Pese a ello, sus pasos se han reconducido a los términos actuales del principio de confianza legítima, cerrando para el non venire las posibilidades de alcance a la potestad reglamentaria; pues su cometido esencial es la validación de la congruencia entre actuaciones anteriores y posteriores.

Otro de los elementos significativos en cuanto a la aplicación del principio y en franca relación con la lesividad, como ya se ha referido, tiene que ver con el manto de aplicabilidad del mismo: ¿actos irregulares o actos eficaces? El recorrido tampoco ha sido uniforme, si bien ha tenido aplicabilidad para ambos supuestos, el surgimiento de técnicas como la revisión de oficio ha ido cercenando los espacios de aplicación al acto irregular y dejando terreno al acto eficaz. Así ha sido resumido "el non venire lo que pretendía precisamente era la continuidad del acto anterior, lícito o no, mientras que la revisión lo que pretende es exactamente lo contrario, su eliminación"16.

El segundo principio relacionado con el tema y de imprescindible revisión es el principio de irrevocabilidad de los actos administrativos favorables, por el cual en líneas muy

\footnotetext{
15 Sin ahondar demasiado en el acto administrativo, porque para él es evidente la aplicación del principio, centrémonos en el particular de la norma jurídica; así queda referido "en el caso del efecto reflejo de las normas, la calificación jurídica de esta posición que se atribuye a un sujeto es distinta. Se trata solamente de una situación jurídica de ventaja o sujeción producida en dicho sujeto como consecuencia de la aceptación derivada del efecto que la norma o regla ha provocado en un determinado sujeto y ha generado un concreto estado que le permite de ahí meros intereses (...) y que derivadamente ha generado un estatus fáctico aceptado, que después ya se quiere que sea también aceptable jurídicamente". José Eugenio SORIANO GARCÍA, " "Non venire» contra factum proprium. (Un préstamo civilista devuelto a su lugar original en la teoría de las fuentes del Derecho)" en Juan Alfonso SANTAMARÍA PASTOR (Dtor), Los principios jurídicos del Derecho administrativo, Editorial La Ley, grupo Wolters Kluwer, España, 2010, pp. 430 y 431.
}

16 Idem, pp. 432-433. 
esquemáticas, se "veta a la Administración pública que ha dictado un acto o cuya inactividad ha dado lugar al nacimiento de un acto que favorece a uno o varios interesados bien al eliminarlo, de oficio, definitivamente, en todo o en parte, sea suprimiéndolo, sea substituyéndolo por otro, bien al instar su eliminación por la jurisdicción contencioso administrativa". ${ }^{17}$

Por supuesto, este principio encuentra, en el interés público un límite objetivo, excepcionando en los casos de su afectación, sin que ello implique desprotección para el administrado a quien se le modificará su status.

Lo anteriormente expuesto queda como afluente para el reconocimiento de un principio que permite englobar las posibles situaciones generadas, y es que ambos descansan en el ideal de buena fe que da lugar a la idea general de la validez de los actos administrativos; y como referente para evaluar que, si una actuación inicial era aparentemente correcta, lícita y devenía en acto favorable al administrado, entonces sale a escena el non venire ${ }^{18}$.

\section{EI proceso de lesividad: de su instrumentación}

La lesividad toma cuerpo y se instrumenta a partir de lo que se ha reconocido como la vía, el proceso o juicio de lesividad. Gustavo A. ESQUIVEL VÁZQUEZ, expresa que "el proceso o juicio de lesividad es el intentado por una autoridad administrativa dentro del proceso contencioso administrativo, con el propósito de anular una resolución favorable a un gobernado, que fue emitida de manera ilegal". ${ }^{19}$

Andrés SERRA ROJAS, sostiene que "el procedimiento de lesividad en la doctrina administrativa es un procedimiento administrativo especial, iniciado por la Administración Pública

\footnotetext{
17 Marcos ALMEIDA CERREDA, "El principio de irrevocabilidad de los actos favorables”, en Juan Alfonso SANTAMARÍA PASTOR, ob.cit., p. 1106.

18 Ibidem p. 41.

19 Gustavo ESQUIVEL VÁZQUEZ, El juicio de lesividad y otros estudios, $1^{\text {a }}$ ed. Porrúa, México, 2002, p. 66.
} 
para revocar o nulificar un acto administrativo dictado por la misma autoridad, por error o porque perjudique al fisco". ${ }^{20}$

El autor español Aurelio GUAITA define la lesividad administrativa como "un proceso administrativo especial, promovido por un sujeto jurídico- administrativo, en demanda de que se revoque un acto administrativo anterior de aquel mismo sujeto público". ${ }^{21}$

Por su parte el autor Jesús GONZÁLEZ PÉREZ cataloga al recurso de lesividad como: "Aquel proceso administrativo especial cuyo objeto es la pretensión deducida por una entidad pública en relación a un acto de la misma". ${ }^{22}$

José Roberto DROMI CASAS manifiesta que: "La lesividad está reservada para los casos en que la «administración autora de algún acto pretendiere demandar ante la jurisdicción contencioso-administrativa su anulación” ... La interposición de la acción de lesividad da lugar a un proceso jurisdiccional en el que se examina la pretensión deducida por un sujeto de derecho frente a otro". ${ }^{23}$

Alejandro NIETO, por su parte, sostiene que conforme a su terminología: "el concepto de lesividad administrativa está constituido por dos elementos: a) la lesión, como hecho en sí; b) la lesión, como violación jurídica; suponiendo el primero una declaración formal, objetiva y económica, que debe hacerse por la propia Administración..., y en cuanto al segundo de los requisitos, es decir, la lesión con violación jurídica, no cabe olvidar que aquel daño, aquella disminución lesiva en el patrimonio, debe ser contraria a la Ley y, por tanto, antijurídica". ${ }^{24}$

20 Andrés SERRA ROJAS, Derecho Administrativo, Segundo curso, 23 ed. Porrúa, México, 2001, p. 831.

21 Aurelio GUAITA MARTORELL, El proceso de lesividad, $3^{\mathrm{a}}$ ed. Bosch, Casa Editorial Barcelona, 1980, p. 74.

22 Jesús GONZÁLEZ PÉREZ, ob.cit., p. 68.

23 José Roberto DROMI CASAS, "Acción de lesividad" en Revista de Administración Pública, No. 88, Enero- Abril, Instituto de Estudios Políticos, Madrid, 1979. pp. 209-210.

24 Alejandro NIETO, "Lesividad y expropiación", en Revista de Administración Pública, №. 36, Septiembre-Diciembre, Madrid, 1961, p. 132. 
Como puede apreciarse, con sus matices, los criterios sobre el proceso, procedimiento, o recurso de lesividad, mantiene intangible la idea de la necesidad de revocación de un acto administrativo por la Administración que lo dictó. Las razones de revocación varían en los criterios doctrinales, pero en cualquier caso, subyace la idea de desconocer un derecho reconocido a un administrado. "Constituye, por un lado, una excepción a los principios característicos del régimen administrativo-dentro del cual la Administración goza del privilegio de actuar por sí las pretensiones - y por otro, una excepción a otro principio tradicional del Derecho administrativo-la irrevocabilidad de los actos administrativos declaratorios de derechos-". 25

Un elemento singular se añade para las razones del proceso: ¿se trata de un acto eficaz? ¿se refiere a un acto viciado? Sin dudas, bajo cualquiera de las posibles respuestas se trata de un acto que devino en lesivo al interés general. GARCÍA TREVIJANO $^{26}$ afirma que el proceso de lesividad ha quedado constreñido a los supuestos de lesiones económicas y vicios de oportunidad, pero en ambos casos sin ilegalidad.

En la doctrina cubana, ÁLVAREZ TABÍO, manifiesta que:

“(...) a virtud de la teoría de los actos propios, que constituye un principio cardinal de Derecho administrativo, constantemente sancionado por la jurisprudencia, la Administración no puede volver gubernativamente sobre sus propios actos. Pero como, por otra parte, sería absurdo mantener una situación ilegal, tan pronto la Administración descubre sus propios yerros, debe estar facultada para someter a revisión aquéllos actos que resulten perjudiciales a sus intereses". ${ }^{27}$

\footnotetext{
25 Jesús GONZÁLEZ PÉREZ, "El proceso de lesividad" en Revista de Administración Pública, No. 25, Enero- Abril, Instituto de Estudios Políticos, Madrid, 1958, p. 128.

26 Landelino LAVILLA ANSINA, "La revisión de oficio de los actos administrativos" en Revista de Administración Pública No. 34, Enero-abril, Instituto de Estudios Políticos, Madrid, 1961, p. 64.

27 Fernando ÁlVAREZ TABÍO, "El proceso Contencioso Administrativo Doctrina, Legislación, Jurisprudencia", Librería Martí, La Habana, 1954, pp. 52-56.
} 
Por otro lado, existen dos teorías que sustentan posturas diferentes sobre la eficacia del acto o negocio administrativo sometido a una declaración de lesividad: la primera de estas, conocida como status quo expone que la declaración de lesividad no modifica el estado de derecho creado por el acto declarado lesivo, si estaba en ejecución continuará ejecutándose y si estaba en suspenso continuará suspendido; la segunda nombrada novatorio se basa para su formulación en que al declararse lesivo un acto sus efectos se suspenden. La doctrina ha utilizado indistintamente ambos criterios, sin que exista un consenso para la implementación de uno o de otro, sin embargo, el criterio novatorio es utilizado con mayor frecuencia. En nuestro país, es este el criterio que prima basado en que la Administración Pública para la satisfacción del interés público no puede supeditarse a los intereses del particular de que se ejecute el acto declarado lesivo, y además porque la Administración goza del privilegio de presunción legalidad de sus actos y de previa ejecutoriedad de los mismos.

La Ley número 7 de 19 de agosto de 1977, Ley de Procedimiento Civil, Administrativo y Laboral, en su artículo 666.2 establece:

2. la Administración contra su propia resolución firme que haya creado un derecho de carácter subjetivo, siempre que el órgano supremo de la jerarquía administrativa o el Comité Ejecutivo ${ }^{28}$ del órgano provincial o municipal del Poder Popular de donde emanase aquélla haya declarado, en resolución fundada, que la misma es lesiva a los intereses públicos al objeto de impugnarla en la vía jurisdiccional. Esta declaración deberá hacerse dentro del plazo de tres meses a contar de la fecha en que hubiera sido dictada la resolución.

Ninguno de los órganos inferiores podrá impugnar por sí mismo, las resoluciones de la Administración.

28 Con la Ley de Reforma Constitucional de 1992 se crearon las Administraciones Locales que sustituyeron los Comités Ejecutivos de los órganos locales del Poder Popular. 
A partir de este artículo se construye en nuestra norma adjetiva el denominado proceso de lesividad, donde la parte demandante siempre va a ser la Administración, quien en virtud del principio de que nadie puede ir contra sus propios actos debe acudir a sede judicial para solicitar la revocación de una decisión que ella misma ha tomado, alegando para ello que, el acto realizado es contrario a los intereses públicos. En consecuencia, se erige como parte demandada en el proceso de lesividad "la persona que resultare beneficiada por la resolución declarada lesiva", ${ }^{29}$ pues le corresponde a la persona titular de la situación jurídica subjetiva reconocida en el acto impugnado, la defensa de sus intereses y del acto mismo.

En tal sentido el Tribunal Supremo Popular en la sentencia 527 de 31 de mayo de 2005, confirma que la declaración de lesividad es un presupuesto del ejercicio de la acción revocatoria, al señalar que: " (...) en aras de los principios de estabilidad y seguridad jurídicas a la Administración no le es dable ir contra sus propias resoluciones firmes y ejecutorias, creadoras de derechos subjetivos, debiendo espetarlas si no acuda al proceso previo de lesividad, por tratarse de actos propios optativos firmes y consentidos (...)"30.

Con un término bastante reducido (3 meses) para la declaración de lesividad, una vez realizada, la Administración cuenta para interponer la demanda con un plazo de 20 días contados a partir del día siguiente de haberse declarado lesiva a los intereses públicos la resolución impugnada; la demanda lleva como uno de los requisitos esenciales para su interposición, la presentación de una copia certificada de la resolución en que se haya hecho la declaración de lesividad. ${ }^{31}$

\footnotetext{
29 Artículo 667.2, Ley No. 7 de Procedimiento Civil, Administrativo y Laboral.

30 Citado por Benjamín MARCHECO ACUÑA, El proceso administrativo cubano en los principios del siglo XXI, una nueva mirada a sus fundamentos jurídicos. Editorial Académica española, Alemania, 2012, p. 55.

31 Artículo 675: Cuando sea la Administración la que demande contra su propio acto, deberá acompañar con el escrito de demanda, el expediente administrativo y una copia certificada de la resolución en la que se haya hecho la declaración de lesividad.
} 
Resalta, como ya apuntábamos, el término para la declaración de lesividad, reducido no sólo desde una perspectiva comparada - en la que la mayoría de los ordenamientos establece entre 1 y 3 años para la declaración de lesividad - , sino también desde la objetividad de la vida cotidiana, en que muchas veces transcurre este término y aún el administrado no está en ejercicio de su derecho reconocido. En relación a si la Administración tiene la posibilidad de promover nueva declaración de lesividad sobre el mismo asunto ante la no formulación de la demanda dentro del plazo concedido para ello, nuestra Ley de Procedimiento Civil, Administrativo, Laboral y Económico, sigue la postura doctrinal de GONZÁLEZ PÉREZ, quien sostiene que: "cuando la declaración de lesividad es válida no puede repetirse, aunque al formularla distintas veces esté vigente el plazo (...) marcado en la ley, y... el término para presentar la demanda arranca de la mencionada declaración una vez adoptada en las debidas condiciones." ${ }^{2}$

\section{III.a) Tratamiento práctico de la lesividad administrativa en Cuba}

El tratamiento primario de la lesividad en nuestro ordenamiento jurídico, se corresponde, con las disposiciones que de España se hicieron extensivas a las provincias de Ultramar. El reconocimiento de la irrevocabilidad de los actos administrativos desde el siglo XIX, se extiende a la Isla por Real Orden de 31 de diciembre de 1876, donde se advertía que: "Es principio legal consignado en el art. 77 de la ley municipal que los acuerdos de los Ayuntamientos en materia de su exclusiva competencia son inmediatamente ejecutivos, salvo los recursos que la misma ley establece. Consecuencia lógica de este principio es que tales acuerdos no puedan revocarse por la Autoridad que los dicta mientras no adolezcan de vicio que los invalide, especialmente si por ello se hacen declaraciones de derechos que causen estado"33.

\footnotetext{
32 GONZÁLEZ PÉREZ, "La declaración....", ob. cit., p. 65.

33 ALMEIDA CERREDA., ob.cit, pp. 1108-1109.
} 
La jurisprudencia cubana en materia de lesividad administrativa, demuestra que dicho recurso fue muy utilizado a partir del siglo XX, ejemplo de ello constituyen un sin número de sentencias que abordaban este tema. La declaración de lesividad como requisito previo para la interposición ante los tribunales competentes del proceso de lesividad, a decir del autor cubano Manuel BUSTELO VÁZQUEZ, podía a la altura del año 1901 realizarse por la Administración central del Estado o por las administraciones provinciales y municipales ${ }^{34}$; aspecto que a su vez permaneció invariable durante el período de aplicación de la Constitución de 1940.

La facultad de declarar la lesividad por la Administración central se reconoció por el derecho positivo cubano, en la Ley del Procedimiento Contencioso Administrativo, según la cual el plazo para interponer el recurso contencioso administrativo la Administración, será también de tres meses contados desde el día siguiente a la declaración por quien corresponda, de la lesividad de la resolución impugnada. Ello implica que dicha facultad no se encontraba atribuida a una autoridad determinada, sino que es el Presidente de la República, como autoridad máxima en orden administrativo, quien se encargaba de su ejercicio.

El artículo 6 del Reglamento del Procedimiento Contencioso Administrativo de 1889 se mantuvo implícito en la potestad del Presidente de la República en el artículo 142 inciso a) de la Constitución de 1940 y en, precepto constitucional que establecía:

“(...) Corresponde al Presidente de la República asistido del Consejo de Ministros, sancionar y promulgar las leyes, ejecutarlas y hacerlas ejecutar; dictar, cuando no lo hubiere hecho el Congreso, los reglamentos para la mejor ejecución de los mismos; cuando incumba al gobierno y administración del Estado, fuere conveniente sin contravenir en ningún caso, lo establecido en las leyes. Y el Reglamento del procedimiento Contencioso

34 Aún en el año 1901, estaba en vigor la Ley SANTAMARÍA DE PAREDES. 
Administrativo determina que las resoluciones dictadas por un Secretario del Despacho no podrían ser reclamadas en vía contenciosa por Secretario de distinto Ramo; que tampoco podrían ser reclamadas por las Autoridades inferiores, ni por los particulares, cuando obran por delegación o como meros agentes o mandatarios de la Administración." 35

La Administración central, para declarar la lesividad de sus actos tenía que cumplir los siguientes requisitos o formalidades:

1. Debía dictarse un Decreto del Presidente de la República, el que a su vez debía estar refrendado por el Ministro del Ramo $^{36}$ correspondiente y con la visa del Primer Ministro.

2. Recaía sobre un acuerdo de la Comisión, y no sobre la resolución o el decreto de separación.

Según lo expresado por BUSTELO VÁZQUEZ, desde el punto de vista de la Administración, la rescisión por lesión constituye la revocación de un acto suyo, y ésta solo puede verificarse mediante un acto contrario de voluntad.

La Administración central podía declarar la lesividad de los actos realizados por la administración provincial y la municipal en los casos en que actuaba la primera como Delegado del propio Ejecutivo Nacional y en el segundo como agente del Poder Ejecutivo Nacional en el respectivo término municipal. Sin embargo, en materia contractual no sucedía lo mismo a tenor de lo previsto en el artículo $5^{\circ}$ de la Ley SANTAMARÍA DE PAREDES ${ }^{37}$, pues los contratos no tenían que ser objetos de declaración de lesividad.

\footnotetext{
35 Artículo 142, inciso a) de la Constitución de 1940, citado por BUSTELO VÁZQUEZ, La lesividad de los..., ob. cit., p. 80.

36 El Ministro del Ramo es aquel que haya dictado el acto que se declare lesivo, o el que sea superior jerárquico del funcionario que lo hubiese dictado, o el del Ministerio al que está adscripto el organismo de que el acto proceda, según BUSTELO VÁZOUEZ, La lesividad de los..., ob. cit., p. 81.

37 La Administración activa tiene el derecho de adoptar en los contratos de servicios públicos las resoluciones que estime procedentes respecto a su cumplimiento, inteligencia,
} 
De lo hasta aquí abordado, se concluye que en la Administración central la declaración de lesividad solo podía hacerse por el Presidente de la República dentro del año siguiente a la fecha de la resolución a que se refiere y una vez agotado este término sin declararse la lesividad de la resolución se consideraba firme y consentida.

La Administración provincial, por su parte, tenía la facultad de declarar la lesividad cuando:

"resultare perjudicial al interés de la Provincia algún contrato o acuerdo, el Consejo podrá declararlo lesivo, dentro del plazo de cinco años, aunque se haya creado derecho de tercero, pero deberá interponerse por el Gobernador de la Provincia en tiempo y forma, después de hecha la citada declaración, demanda contencioso administrativa, solicitando la rescisión, ante la audiencia correspondiente." 38

La declaración de lesividad por los municipios, tenía al igual que en las provincias el mismo plazo de cinco años, aspecto que regula la Ley Orgánica de los Municipios, en su artículo 268 que estableció:

"cuando resulta perjudicial al interés del Municipio algún contrato municipal o algún acurdo del Ayuntamiento, éste podrá declararlo lesivo dentro del plazo de cinco años, aunque exista derecho de tercero, deberá interponerse en tiempo y forma después de hecha la citada declaración, la demanda contencioso-administrativa, solicitando la rescisión ante la Audiencia de la Provincia correspondiente." ${ }^{39}$

\footnotetext{
rescisión y efectos, sin perjuicio de los recursos que pueden utilizar los interesados que estimen vulnerados sus derechos, puede lícitamente declarar la inexistencia legal del contrato celebrado para la construcción de una carretera.

38 Véase artículo 120 de la Ley de las Provincias de 1908. Éste precepto se reprodujo en la Ley Provincial de 1950, específicamente en su artículo 115, aunque suprimió lo referente a la interposición de la demanda por el Gobernador de la provincia.

39 BUSTELO VÁZOUEZ, La lesividad de los..., ob. cit., p. 88.
} 
Solo podían declarar la lesividad de acuerdos o contratos de las esferas municipal y provincial, el Ayuntamiento y el Consejo Provincial respectivamente, lo que implicaba que siempre se realizara por el superior jerárquico.

La declaración de lesividad recaía sobre acuerdos del Ayuntamiento o sobre contrato celebrado por el Municipio. Los acuerdos del Ayuntamiento eran actos jurídicos que podían revestir índole legislativa o solo administrativa. La declaración de lesividad se caracterizó por su carácter general, con fuerza obligatoria objetiva dentro del territorio del Municipio, en ejercicio de las atribuciones que le señala el artículo 126 de la Ley Municipal y constituyeron actos administrativos cuando determinaban sobre una materia singular, declarando, reconociendo, modificando o extinguiendo derechos subjetivos. La declaración de lesividad solo recaía sobre los acuerdos que constituyeran actos administrativos, no sobre aquellos que se adoptaran para el ejercicio de las atribuciones que la ley confería al Ayuntamiento como órgano legislativo del Municipio, en estos últimos la revocación es libre. ${ }^{40}$

Los contratos son actos bilaterales y no son susceptibles de revocación. Por Contrato municipal se entendió: “ (...) en el sentido de contrato administrativo celebrado por el Municipio

40 Respecto a este tema el Tribunal Supremo se ha pronunciado mediante las sentencias 75 de 16 de enero, 103 de 21 de enero, 218 de 6 de febrero, 219 de 9 de febrero, 13 de febrero y 266 de 13 de febrero, todas de 1953, del modo que sigue:

"Como se ha declarado reiterada y razonadamente, a los fines de la impugnación que autoriza el artículo 217 de la Constitución respecto de acuerdo o resolución municipal, no se requiere no procede previa declaratoria de lesividad por parte del Presidente de la República, así como que el plazo de tres meses para la interposición del recurso no está subordinado a dicha declaratoria, por lo que basado en criterio contrario el motivo de casación, citándose como infringido el artículo séptimo de la Ley de lo Contencioso administrativo que no ampara la tesis de dicho motivo, resulta forzosa la desestimación del mismo".

Tomado de Gustavo, RAMÍREZ OLIVELLA, Diccionario de Jurisprudencia Contenciosoadministrativa, Repertorio por orden alfabético de materias, de todas las decisiones del Tribunal Supremo de Cuba al resolver los recursos de casación, apelación y queja en la jurisdicción contencioso-administrativa, desde Enero de 1953 y hasta diciembre de 1957, ambos meses inclusive, Jesús Montero Editor, La Habana, 1958, p. 367. 
como entidad o poder público, no comprendiendo los que el mismo pueda celebrar como persona jurídica, los cuales están excluidos de la vía contencioso administrativa." ${ }^{41}$

Las resoluciones del Gobernador Provincial y las del Alcalde Municipal no constituían objeto de declaración de lesividad. Si lesionaba algún interés particular, el administrado que resultase afectado por ellas podía reaccionar por medio de los recursos que las leyes conceden, en caso contrario ni el Ayuntamiento, ni el Consejo provincial podría ejercer control sobre las mismas respecto al Alcalde y al Gobernador, respectivamente.

En relación con el momento en que comenzaba a decursar el plazo para establecer la declaración de lesividad en ambas instancias (municipal y provincial), el autor cubano Manuel BUSTELO VÁZQUEZ refiere que en el caso de los acuerdos el término comenzaba a correr a partir de que quedara válidamente manifestada la voluntad del órgano deliberante, por la concurrencia de los elementos materiales y formales que lo integran. ${ }^{42}$ $\mathrm{Y}$ en igual sentido se pronuncia en torno a los contratos administrativos, afirmando que el término corría desde que median el consentimiento, el objeto y la causa, salvo, que, además, la ley exija como esencial alguna forma solemne. ${ }^{43}$

La facultad de declarar lesivos los actos administrativos era limitada, en la esfera de la administración municipal, en el sentido de que dicha declaración no se realizaba sobre acuerdos que hubieren sido confirmados a virtud de demanda o de recursos interpuestos contra ellos, o por suspensión revocada de los mismos. Igual pronunciamiento estableció la ley Orgánica de las Provincias, en relación a la Administración provincial.

La declaración de lesividad podía hacerse aunque existiera derecho de un tercero. Si no existiese derecho de un tercero

\footnotetext{
41 BUStelO VÁZQUEZ, La lesividad de los..., ob. cit., p. 91 citado del art. 4 inciso $2^{\circ}$ Ley del Procedimiento Contencioso Administrativo.

42 Idem., p. 92.

43 Ibíd., p. 92.
} 
el Ayuntamiento y el Consejo provincial podrían revocar libremente sus acuerdos y adoptar cualquiera otra medida o disposición contraria. No sería en tal supuesto necesaria una declaración de lesividad. La existencia de un derecho subjetivo no puede referirse si no a un acto o acuerdo firme que hubiese causado estado, pues las declaraciones o reconocimientos sostenidos en un acto sujeto a recurso o demanda de revocación no originaban derecho alguno.

Cuando se probaba ante el Tribunal la lesión, se rescindía el contrato o se dejaba sin efecto la resolución de que se trataba, determinándose además cuanto estimaba procedente y equitativo sobre indemnización y sobre derechos adquiridos por tercera persona; distinguiendo así la diferente posición en que se encontraba la persona directamente interesada en el acuerdo o contrato, y el tercero para quien se derivó, de uno u otro, derechos subjetivos.

Tanto en las Provincias como en los Municipios, de acuerdo a sus leyes orgánicas, los efectos que producía la confirmación por un Tribunal de la lesividad administrativa, era en relación a los contratos, su rescisión y en cuanto a las resoluciones, su ineficacia.

Ahora bien, en torno a la formulación de la declaración de lesividad de los acuerdos y resoluciones municipales, debemos destacar que no era aplicable lo establecido en el párrafo final de la Ley SANTAMARÍA DE PAREDES, en relación al término en el cual la Administración podía utilizar el recurso contencioso-administrativo, ${ }^{44}$ pues este trámite previo solo era requerido en el supuesto de ser de la propia Administración el acto por el que se iba a acudir en la vía judicial, lo que no acontece cuando emanaba de la Municipal o Provincial que gozaban de expresa autonomía por la Constitución y en consecuencia el plazo para formular la impugnación mediante el recurso contencioso-administrativo, con aplicación al efecto

44 Este plazo se empezaba a contar según la citada norma desde el día siguiente a la declaración de lesividad corresponda. 
del Decreto número 3251 de 1941 era de tres meses a contar desde que quedó notificado el Ejecutivo Nacional del acuerdo o resolución y no el de un año que señalaba el artículo tercero del mencionado Decreto, cuyo conflicto con el artículo séptimo de la invocada ley en su párrafo primero, obligaba a estar a lo dispuesto en este último por su mayor fuerza obligatoria.

Las sentencias número 102 y 105 de 21 de enero de 1953, al igual que la 329 de 25 de febrero de 1953 y 1173 de 14 de noviembre de 1957, todas del Tribunal Supremo, coincidían en los aspectos antes expuestos. En igual sentido se pronunció la sentencia No 109 de 21 de enero de 1953, relacionada con la impugnación de un acuerdo municipal por el Presidente de la República, la declaración de lesividad y el término para interponer recurso contencioso-administrativo, la que se fundamentó en los hechos siguientes:

"Habiendo acordado el Ayuntamiento de Máximo Gómez crear un impuesto de catorce pesos mensuales para todo carro o vendedor que no siendo local venda galletas y pan no elaborados en la localidad, el Presidente de la República lo declaró lesivo y el Fiscal, estableció recurso contencioso-administrativo en el que reclamó la revocación de la resolución interpelada; y en consecuencia el Tribunal Supremo resolvió como sigue:

Considerando que como se tiene con reiteración declarado ni el Decreto Presidencial número tres mil doscientos cincuenta y uno de mil novecientos cuarenta y uno, ni los preceptos constitucionales contraídos al derecho de impugnación de que se trata ni en las Leyes que tiene relación con el problema, existe precepto alguno que pueda servir de apoyo a la tesis de la necesidad de una previa declaratoria de ser el acuerdo lesivo al interés público para poder formular la impugnación y no correr el término señalado en el artículo séptimo de la ley de la materia sino a partir de dicha declaratoria, y resulta por lo contrario, de los preindicados textos que carece de justificación cuando no de posibilidad legal, 
tal declaratoria, que recaería sobre actos o acuerdos de otra Administración.

Considerando que basada la infracción que se denuncia del artículo séptimo de la ley de la materia como actualmente rige en que el acuerdo del Ayuntamiento de Máximo Gómez fue declarado lesivo a los interés públicos pretendiéndose computar el término de tres meses que concede la Ley para acudir a esta vía a partir de la fecha de la declaratoria de lesividad, es clara la aplicación del criterio expuesto, que debe ser ratificado por esta resolución, debiendo en consecuencia, desestimarse el recurso de casación por infracción de ley que interpone el Ministerio Fiscal.

Considerando que no procede imponer costas porque recurre el Ministerio Fiscal, de conformidad con lo establecido en la orden de Casación artículo cuarenta de la misma (por cuanto) ni las cobra ni las devenga.

Fallamos no haber lugar al recurso, sin especial condena de costas.

Santiago Rosell, Presidente; Pedro Cantero, (ponente); Juan F. Torres; Gustavo Ramírez Olivella; Guillermo Portela; Manuel G. Miranda; Maximiliano Smith; Magistrados.”

En relación a esta propia sentencia (109 de 21 de enero de 1953), el autor Gustavo RAMÍREZ OLIVELLA realizó el siguiente comentario:

"Como se tiene declarado con reiteración, ni el Decreto presidencial número 3251 de 1951, ni los preceptos constitucionales contraídos al derecho de impugnación de que se trata, ni las leyes que tienen relación con el problema, contienen precepto alguno que pueda servir de apoyo a la tesis de la necesidad de una previa declaratoria de ser el acuerdo lesivo al interés público para formular la impugnación y no correr el término señalado en el artículo séptimo de la Ley de la materia, sino a partir de dicha declaratoria, y resulta por lo contrario, de los indicados textos que carece de justificación cuando no 
de posibilidad legal, tal declaratoria, que recaería sobre actos o acuerdos de otra Administración." ${ }^{45}$

Ello evidencia que no existía aún un criterio unánime sobre el tratamiento de la lesividad administrativa a partir de las formulaciones que existían - en relación a este tema- en las normas vigentes en Cuba.

Algunos de los fallos del Tribunal Supremo ${ }^{46}$ en relación a la lesividad administrativa respondían a la estabilidad de la resolución administrativa y en específico, en cómo ésta podía verse afectada por el erróneo cómputo del término que poseía el Presidente de la República para iniciar el procedimiento contencioso administrativo, pues siendo el plazo establecido el de tres meses según lo estipulado en el artículo séptimo de la Ley de 13 de septiembre de 1888, en la práctica se contaba el término a partir del momento en que el Presidente conocía de la resolución; aspecto que no poseía amparo legal y por ende podía catalogarse como un actuar indebido de la Administración.

La jurisprudencia cubana sentó como cuestión principal a dirimir ante la interposición del proceso de lesividad, lo relativo al cómputo del término para interponer la demanda. Es por ello que la sentencia 273 de 25 de mayo de 1939 estableció como única condición para la declaración de lesividad de la resolución gubernativa -previa su impugnación por la Administración-, la del término señalada para hacerla, pues fuera de este quedaría firme y consentida. ${ }^{47}$

Ya en los años 40, la Audiencia de la Habana y el Tribunal Supremo fueron los órganos encargados del conocimiento del proceso de lesividad, el cual nacía en la mayoría de los casos por la cesantía de los empleados públicos y por violaciones de

\footnotetext{
45 Gustavo RAMíREZ OLIVELLA, Diccionario de..., ob. cit., p. 368.

46 Ibíd., p. 370. (comentarios de la sentencia 789, de 19 de mayo de 1955).

47 Véase Guillermo DE MONTAGÚ Y VIVERO, Jurisprudencia del Tribunal Supremo de Cuba. En materia civil. Hipotecaria. Contencioso-administrativa y de constitucionalidad, 19391943, Tomo V, Cultural S.A, La Habana, 1948, p. 621.
} 


\section{la Administración en cuanto a la revocación de sus actos por si misma cuando debía surgir el mentado proceso.}

En tal sentido existen muchos pronunciamientos del Tribunal Supremo, donde se vinculó la lesividad administrativa con el principio de irrevocabilidad de los actos administrativos, ejemplo de ello es la sentencia No. 770 de 9 de diciembre de $1948^{48}$.

48 Esta sentencia fue revocada por el Tribunal Supremo, basado en los fundamentos que reproducimos a continuación y que fue publicada en La Jurisprudencia al día. Contencioso, Hipotecario. Acuerdos. S. de Gobierno. La Habana. 1951. p. 442-445:

Considerando que según ha declarado el tribunal supremo en su sentencia número setecientos setenta de nueve de diciembre de mil novecientos cuarenta y ocho, consecuente con el principio de irrevocabilidad de los actos administrativos, la Administración para invalidar esos actos debe declarar la lesividad, como medida previa y necesaria para interesar después su revocación por los Tribunales, a cuyo efecto el párrafo final del artículo siete de la Ley trece de septiembre de mil ochocientos ochenta y ocho, tal como quedó redactado por el Decreto-Ley seiscientos cuarenta y nueve de mil novecientos treinta y seis, ofrece reglas y plazos para impugnar sus propias resoluciones en la expresada vía cuando las estime contrarias o perjudiciales a los intereses públicos.

Considerando que dentro de este concepto de irrevocabilidad de la resolución administrativa, cuando fuere definitiva y declaratoria de derechos, se comprende indudablemente la imposibilidad de su suspensión por el mismo Poder que la dictó pues ella a tanto equivale como a su revocación temporal, al desconocerse y vulnerarse, en ambos casos, la estabilidad de la decisión gubernativa.

Considerando que tampoco procede estimar en estos casos, según enjuicia el Tribunal Supremo en la invocada sentencia, la discrecionalidad de la medida combatida, pues aunque es cierto que participa de aquel concepto la facultad de la Administración para declarar lesiva una resolución de sus propias autoridades y organismos, no es lo menos de que carece de la facultad de suspenderlas, ya que conforme al artículo cien de la Ley de la materia solo compete a los Tribunales en el caso a que se contrae el párrafo primero de dicho artículo; y si bien con arreglo al propio precepto es la Administración quien resuelve en definitiva cuando el Fiscal se opusiere fundado en que la suspensión puede seguirse un daño al servicio público, o si lo estimare el tribunal no cabe dudar que tal disposición es inatinente al caso en que la recurrente es la Administración misma, así como que ambas situaciones jurídicas solo puede producirse una vez entablado el procedimiento contencioso- administrativo, encaminado a obtener la revocación de la resolución impugnada, pero no, como ocurre en el presente caso, en que la Administración ha decretado la suspensión antes de acudir a la mencionada vía de revisión judicial.

Considerando que por todo lo expuesto procede desestimar las excepciones de incompetencia de jurisdicción y falta de acción opuestas por el Ministerio Fiscal y declarar con lugar en todas sus partes la demanda objeto de este recurso. 
Dentro de este concepto de irrevocabilidad de la resolución administrativa, cuando fuere definitiva y declaratoria de derechos, se comprende indudablemente la imposibilidad de su suspensión por el mismo poder que la dictó, pues ello a tanto equivale como a su revocación temporal, al desconocerse y vulnerarse, en ambos casos, la estabilidad de la decisión gubernativa.

Otro aspecto importante que cabe destacar es lo referente a la revocación por la Administración de sus propios actos declarativos de derechos, sin acudir al proceso de lesividad, máxime cuando el mismo estaba normado. Eco de esta situación fueron muchas sentencias del Tribunal Supremo, en las que se dejó por sentado una y otra vez, que debía realizarse previamente una declaración de lesividad y luego acudirse al proceso contencioso administrativo; y debido al incumplimiento de ello por la Administración Pública, el Tribunal Supremo revocó todas aquellas resoluciones administrativas que hubiesen modificado una resolución contentiva de derechos con anterioridad.

Las decisiones judiciales marcaron pauta en relación al cómputo de los términos para realizar la declaración de lesividad y para la interposición del recurso de lesividad, a partir de la aplicación en nuestro país de la Ley SANTAMARÍA DE PAREDES y del Decreto Ley 649 de 1936; pues siendo el término para formular la declaración de lesividad de un año siguiente a la fecha de la resolución objeto de dicho proceso y el de interposición del recurso de tres meses desde el día siguiente a la declaración, el Tribunal Supremo razonó en sus sentencias que los referidos términos debían computarse tácitamente del modo expresado en las normas y no como en innumerables casos había alegado

Considerando que en su virtud, debe declararse sin lugar el recurso y confirmar la sentencia apelada, sin expresa imposición de costas, por no haberse litigado con temeridad notoria en ninguna de las instancias.

Vistos los preceptos invocados y los demás de general aplicación.

Fallamos que debemos declarar y declaramos sin lugar el recurso y confirmar la sentencia apelada, sin expresa imposición de costas. 


\section{el Fiscal ${ }^{49}$ en representación de la Administración Pública. Estos}

49 El Fiscal en varios supuestos alegó que aún cuando la declaración de lesividad se realizara varios meses anteriores a la culminación del término de un año con que cuenta la Administración para su formulación, debía aguardarse por el transcurso del año completo para comenzar a computar el término en que la Administración contaba para la interposición del recurso. Un ejemplo de ello es la sentencia No 582 de 20 de junio de 1952, que fue tomada de La Jurisprudencia al día. Contencioso-Administrativo, Hipotecaria. Secretaría de Gobierno. La Habana. 1952. Pág. 326-327,la que reproducimos a continuación:

Sentencia No 582 de 20 de junio de 1952. (Leída en audiencia pública el día 8 de agosto.)

Recurso contencioso-administrativo establecido por la Administración.- Declaración de lesividad.- Término para interponer el recurso.

-El término de tres meses que se concede a la administración para establecer el recurso contencioso- administrativo, después de la declaración de lesividad de una resolución, se cuenta desde la fecha misma de esa declaración.

Y no es de aceptar el criterio del fiscal, recurrente, en el sentido de que cuando la declaración de lesividad se haga antes del año señalado, siempre se ha de contar el año entero y a partir de él, contar los tres meses concedidos para interponer el recurso contenciosoadministrativo.

Ordenada por la Comisión del Servicio Civil la reposición de Armando Mujica Vigil, en el cargo que desempeñaba en la Dirección de la Cartera Dactilar del Chofer, del Ministerio de Gobernación, se declaró lesiva esta resolución y el fiscal estableció recurso contenciosoadministrativo.

Dado traslado al empleado, este alegó la excepción dilatoria de incompetencia, por haberse establecido el recurso tres meses y 9 días después de la declaración de lesividad.

La Sala Segunda de lo Civil de esta Audiencia dictó auto declarando con lugar la excepción y en su mérito, declaró su incompetencia para conocer el asunto.

Establecida súplica por el Fiscal, dicha Sala la declaró sin lugar.

El Fiscal, estableció casación, al amparo de la causa 6ª del artículo 1690 de la Ley de Enj. Civil, estimando infringido el artículo $7^{\circ}$, último párrafo, de la ley de lo Contenciosoadministrativo, por aplicación indebida, porque el término de tres meses para interponer el recurso ha de contarse después del año que tiene la Administración para declarar la lesividad.

El Tribunal Supremo resuelve lo que sigue:

Considerando que de conformidad con categórica disposición del último párrafo del artículo séptimo de la Ley trece de septiembre de mil ochocientos ochenta y ocho, tal como quedó redactado por el decreto Ley seiscientos cuarenta y nueve de mil novecientos treinta y seis el plazo para que la Administración pueda utilizar el recurso contencioso-administrativo es el de tres meses contados desde el día siguiente a la declaración por quien corresponda de la lesividad de la resolución impugnada, y si bien, a su vez, esta declaración, con sujeción al propio citado párrafo, deberá hacerse dentro del año siguiente a la fecha de la resolución a que se refiere la cual quedará, si así no se hiciera, consentida y firme, ni la clara letra de la Ley, ni otra alguna autoriza a entender que si la dicha declaratoria de lesividad 
pronunciamientos del Tribunal Supremo resultaron muy certeros, ya que la interpretación errónea de las normas aplicables afectaría a los derechos de los administrados y a los principios de legalidad y seguridad jurídica que deben estar presentes en este tipo de proceso contencioso-administrativo.

La práctica judicial en materia de lesividad administrativa destaca que en los años 50, no existieron procesos de lesividad como tal, sino que ante las violaciones administrativas de revocar per se sus resoluciones, se establecían los correspondientes recursos por los administrados que veían vulnerados sus derechos y finalmente el Tribunal Supremo -basándose en los fundamentos del proceso de lesividad- tomaba una decisión y restablecía la legalidad quebrantada. Luego de revisar las Revistas Cubana de Jurisprudencia de los años 60 y los Boletines del Tribunal Supremo Popular de los años 2000 al 2010, nos percatamos de la exigua, y por momentos, inexistente referencia a la lesividad como proceso. En unión a lo anterior una revisión de los legajos de sentencias de los años 2000-2010, pertenecientes a la Sala de lo Civil y lo Administrativo del Tribunal Provincial Popular de Santiago de Cuba, verificó que durante los años señalados no fueron objeto de debate procesos contenciosos administrativos de lesividad.

No obstante a ello, en la práctica judicial del Tribunal Supremo Popular en materia contenciosa administrativa, debemos

se hace antes de vencer el año concedido para ello, el referido plazo de tres meses para que la Administración pueda acudir a la vía contencioso-administrativa haya de empezar a computarse, no obstante, el vencimiento del año, y no a partir del día siguiente al de la declaración de lesividad, que terminantemente viene preceptuado.

Considerando que, en su virtud, no cometida la infracción que se acusa ni el único motivo del recurso, debe ser éste desestimado, sin que proceda hacer especial condenación de costas por ser recurrente el Ministerio Fiscal.

Fallamos que debemos declarar y declaramos no haber lugar al recurso y no hacemos especial imposición de costas.

Gabriel Pichardo Moya. Presidente; Pedro Cantero; Juan F. Torres; Santiago Rosell, (ponente); Gustavo Ramírez Olivella; Magistrados. 
reverenciar que, en el Boletín de dicha institución correspondiente al año 2012, consta la sentencia número 157 de 29 de febrero de 2012, relacionada con la Inadecuada cancelación del usufructo. Esta sentencia alude, al igual que las analizadas con anterioridad, a la imposibilidad que posee la Administración Pública de ir contra sus propios actos y además indica que la vía de lesividad es la adecuada para someter a valoraciones del órgano jurisdiccional la pertinencia de una actuación administrativa.

En tal sentido, es oportuno reproducir algunos fragmentos de dicha resolución judicial:

VISTO: Por la Sala de lo Civil y de lo Administrativo del Tribunal Supremo Popular el recurso de casación en materia administrativa interpuesto por la Dirección Municipal de la Vivienda de Las Tunas, representada por la Lic. IBM; contra la sentencia número ciento cinco, de fecha diecinueve de diciembre de dos mil once, dictada por la Sala de lo Civil y de lo Administrativo del Tribunal Provincial Popular de Las Tunas en el expediente número ciento diecinueve de dos mil once, en el proceso administrativo establecido por MSP, ama de casa y vecina de X, Las Tunas, contra la Dirección Municipal de la Vivienda de Las Tunas; en que impugnó la resolución número mil seiscientos setenta y cuatro, de fecha veintiuno de julio de dos mil once, dictada por la mencionada entidad, por la que se declaró la cancelación de la condición de usufructuaria gratuita a la no recurrente y de licencia de obra, recurso que tiene por objeto impugnar la sentencia que acogió la demanda interpuesta por MSP y revocó la aludida resolución administrativa, por estimar la parte recurrente que dicha sentencia no se ajusta a Derecho. (...)

LA SALA DE LO CIVIL y DE LO ADMINISTRATIVO DEL TRIBUNAL SUPREMO POPULAR RESOLVIÓ:

CONSIDERANDO: Que el motivo único de que consta el recurso de casación interpuesto por la Dirección 
Municipal de la Vivienda de Las Tunas, invocado al amparo del ordinal primero del artículo seiscientos treinta de la Ley de Procedimiento Civil, Administrativo, Laboral y Económico, en que se señalan como vulnerados los artículos ciento quince, apartados a y e de la Ley General de la Vivienda, los apartados tercero, incisos a y $\mathrm{b}$, décimo quinto y vigésimo segundo de la Resolución número once de dos mil seis del Presidente del Instituto Nacional de la Vivienda y los artículos sesenta y cuatro, apartado a y sesenta y seis, apartado segundo inciso d, de la Resolución número catorce de dos mil seis del Presidente del Instituto Nacional de a Vivienda, no puede prosperar, en primer orden porque la facultad de cancelar las licencias de obra concedidas así como las autorizaciones de construcción y los certificados de habitables otorgados en los casos que se detecten violaciones o vicios en su tramitación u otorgamiento y también la cancelación del derecho perpetuo de superficie, corresponde a las Unidades Municipales o Provinciales Inversionistas de la Vivienda y no a la recurrente, además de que no puede la Dirección Municipal de la Vivienda volver contra sus actos que causaron estado y privar por sí y ante sí a la no recurrente de la condición de usufructuaria gratuita de la vivienda objeto del proceso, sin observar el procedimiento previo de declaración de lesividad a que se contrae el artículo seiscientos sesenta y seis, apartado segundo, de la ley rituaria, ni justifica el carácter estatal del inmueble que el órgano depositario de la representación del interés público actúe a su libre albedrío soslayando los derechos que corresponden a los ciudadanos, establecidos por actos de la propia entidad; cuestión insostenible que atentaría contra la más elemental seguridad jurídica y sentido de justicia; en cuya virtud, en modo alguno se encuentran presentes en la sentencia interpelada 
las infracciones denunciadas y el motivo es improcedente. $(\ldots)^{50}$.

\section{Parcialmente, unas conclusiones}

La vía de lesividad constituye, en todo su esplendor, una garantía verdadera para el proceder de la Administración Pública. Un instrumento eficaz en la defensa del interés público defendido y gestionado por el ente administrativo. La realidad jurídica cubana actual ha demostrado no sólo un olvido de esta institución, sino una preterición - sin ánimo de pecar de absolutos - imperdonable.

Muchas podrían ser las causas de esta situación, desde la concepción "dominante" con que nació permeada la Administración Pública posrevolucionaria, hija de unos tiempos y unas coyunturas excepcionales que fueron afianzando en la Administración un papel de ente todopoderoso e inescrutable; hasta la tibieza con que nuestro contencioso administrativo enfrenta, con los ojos puestos en el ayer, una realidad jurídica totalmente diferente a la que le vio nacer. Lo cierto es que pareciera, con este abandono, que nuestra Administración no se enfrenta a la realidad de una vida social en la que no han de ser pocos los supuestos en que se precisa de un instrumento jurídico como la lesividad para resolver las problemáticas derivadas de las coyunturas. Parecería que el principio del "non venire" sostuviera de tal manera las decisiones de la Administración, que bajo ningún concepto pudiera volver sobre sus pasos. En medio de todo ello, la indiferencia hacia la lesividad, lejos de elevar el rol de la Administración, lo hace descender: ¿qué se puede esperar de una Administración que no yerra? ¿Es posible creer que sus actos anteriores nunca han puesto en juego el interés público,

50 Sentencia número 157 de 29 de febrero de 2012, tomado del Boletín del Tribunal Supremo Popular, Cuba, 2012. pp. 167-169. 
cuando los hilos que mueven sus estructuras son sujetos sometidos a la apreciación de circunstancias cambiantes? ¿No se trata, o lo que se espera de la Administración, no es que perciba en todo momento las posibles agresiones al interés público? Si damos respuesta a estas interrogantes, entonces comprenderemos la ingratitud con que se ha trabajado una institución que debe ser cada vez más real, y menos utópica en el ordenamiento jurídico cubano. 